\title{
High time resolution fluctuations in volcanic carbon dioxide degassing from Mount Etna
}

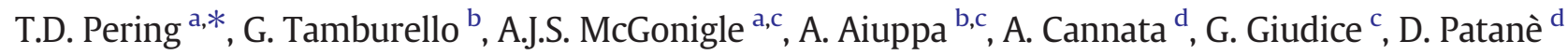 \\ a University of Sheffield, Dept. of Geography, Winter Street, S10 2TN, United Kingdom \\ b DiSTeM, Università di Palermo, via Archirafi, 22, 90123 Palermo, Italy \\ c Istituto Nazionale di Geofisica e Vulcanologia, Sezione di Palermo, Via Ugo La Malfa, 153, 90146 Palermo, Italy \\ d Istituto Nazionale di Geofisica e Vulcanologia, Osservatorio Etneo, Piazza Roma, 2, 95125 Catania, Italy
}

\section{A R T I C L E I N F O}

\section{Article history:}

Received 27 February 2013

Accepted 19 November 2013

Available online 28 November 2013

\section{Keywords:}

Carbon dioxide

Passive degassing

Volcanic remote sensing

Plume imaging

Volcano seismology

\begin{abstract}
A B S T R A C T
We report here on the first record of carbon dioxide gas emission rates from a volcano, captured at $\approx 1 \mathrm{~Hz}$. These data were acquired with a novel technique, based on the integration of $\mathrm{UV}$ camera observations (to measure $\mathrm{SO}_{2}$ emission rates) and field portable gas analyser readings of plume $\mathrm{CO}_{2} / \mathrm{SO}_{2}$ ratios. Our measurements were performedat the North East crater of Mount Etna, southern Italy, and the data reveal strong variability in $\mathrm{CO}_{2}$ emissions over timescales of tens to hundreds of seconds, spanning two orders of magnitude. This carries importantimplications for attempts to constrain global volcanic $\mathrm{CO}_{2}$ release to the atmosphere, and will lead to an increased insight into short term $\mathrm{CO}_{2}$ degassing trends. A common oscillation in $\mathrm{CO}_{2}$ and $\mathrm{SO}_{2}$ emission rates in addition to the $\mathrm{CO}_{2} / \mathrm{SO}_{2}$ ratios was observed at periods of $\approx 89 \mathrm{~s}$. Our results are furthermore suggestive of an intriguing temporal lag between oscillations in $\mathrm{CO}_{2}$ emissions and seismicity at periods of $\approx 300-400 \mathrm{~s}$, with peaks and troughs in the former series leading those in the latter by $\approx 150 \mathrm{~s}$. This work opens the way to the acquisition of further datasets with this methodology across a range of basaltic systems to better our understandingof deep magmatic processes and of degassing links to manifest geophysical signals.
\end{abstract}

(c) 2013 Elsevier B.V. All rights reserved.

\section{Introduction}

Carbon dioxide $\left(\mathrm{CO}_{2}\right)$ is among the most abundant constituents of volcanic gases (Carroll and Holloway, 1994), and exsolves from magmas deeper than other common volatiles such as sulphur dioxide $\left(\mathrm{SO}_{2}\right)$ and water vapour $\left(\mathrm{H}_{2} \mathrm{O}\right)$ (Giggenbach, 1996). Knowledge of $\mathrm{CO}_{2}$ emissions can therefore contribute significantly to our understanding of the movementof magmas in deep volcanic plumbing systems. Hitherto, the measurement of $\mathrm{CO}_{2}$ emission rates has been challenging due to the difficulty of resolving volcanogenic $\mathrm{CO}_{2}$ above high background atmosphericlevels. In consequence, attempts to routinely measure plume $\mathrm{CO}_{2}$ emission rates, particularly at high time resolution, havebeen rather limited (Aiuppa etal., 2006, 2010). Therefore, notwithstandingthe significant contributions made in constraining $\mathrm{CO}_{2}$ emission rates of volcanic plumes at targets such as Mt. Erebus, Antarctica (Wardell etal., 2004), Ol Doinyo Lengai, Tanzania (Koepenick etal., 1996), White Island, New Zealand (Werner etal., 2008), Ruapehu, New Zealand (Werner etal., 2006), Redoubt, Alaska (Werner etal., 2012a,b), Stromboli, Italy (Aiuppa etal., 2010, 2011), Mt. Etna, Italy (Allard etal., 1991) and Kilauea, USA (Poland etal., 2012), these data remain relatively spartan, and in general lack information regarding

\footnotetext{
* Corresponding author at: Department of Geography, Winter Street University of Sheffield, Sheffield, S10 2TN, United Kingdom. Tel.: + 447838219369.

E-mail address: ggp12tdp@sheffield.ac.uk (T.D. Pering).
}

temporal changes. This remains a fundamental weakness in attempts to constrain global volcanogenic $\mathrm{CO}_{2}$ emission rate budgets, in view of which there is a pressing demand for the developmentand application of novel methodologies to improve constraintson spatio-temporal volcanic $\mathrm{CO}_{2}$ degassing and our comprehensionof volcanic systems.

Recently, the Multi-GAS technique (Aiuppa etal., 2005; Shinohara, 2005) has been pioneered to enable rapid measurements of volcanic plume chemical compositions, including $\mathrm{CO}_{2} / \mathrm{SO}_{2}$ gas ratios, leading to significant advances in our understanding of degassing processes. Furthermore, in the last years, UV camera imagery has been applied in volcanology, enabling acquisition of $\mathrm{SO}_{2}$ emission rates with time resolutionsof $\approx 1 \mathrm{~Hz}$, many orders of magnitude faster than possible in the past (e.g., Mori and Burton, 2006; Tamburello etal., 2011a). Here we report on the first volcanic deployment of a novel technique, by which volcanic $\mathrm{CO}_{2}$ emission rates are captured with an acquisition frequency of $\approx 1 \mathrm{~Hz}$, based on the integration of the above two approaches.Such a capability will increase the future potential of linking degassing to geophysical data on unprecedented timescales with significant applicability in improving hazard analysis (Gerlach etal., 2002) and eruption forecasting measures (Aiuppa etal., 2007; Poland etal., 2012).

The $\mathrm{CO}_{2}$ emission rate data were captured during a field campaign on Mt. Etna $\left(37.734^{\circ} \mathrm{N}, 15.004^{\circ} \mathrm{E}\right)$, an alkaline strato-volcano whose $\mathrm{CO}_{2}$-rich magmas (Spilliaert etal., 2006) result in the volcano being the largest time averaged contributor to global volcanic emissions of $\mathrm{CO}_{2}$ (Allard etal., 1991; Gerlach, 1991). Etna currently has four 
degassing summit areas: the South-East crater (SEC), the Central Craters (Bocca Nuova and Voragine), and the North-East crater (NEC) (Fig. 1). Our study is based on passive emissions from the NEC, in recent times one of the most actively degassing vents on Etna (Aiuppa etal., 2008) and the site of recurrent eruptive activity in the last few decades (Allard etal., 2006).

\section{Methodology}

The $\mathrm{SO}_{2}$ emission rates were captured using two Apogee Alta U260 cameras, fitted with 16 bit $512 \times 512$ pixel Kodak KAF-0261E thermoelectrically cooled CCD array detectors. A Pentax B2528-UV lens of $f=25 \mathrm{~mm}$ was attached to the front of each camera, providing $\approx 24^{\circ}$ field of view. The lenses were fitted with filters of $10 \mathrm{~nm}$ FWHM (Asahi Bunko Inc.), one centred around $310 \mathrm{~nm}$, where plume $\mathrm{SO}_{2}$ absorbsincident UV radiation, and the other at $330 \mathrm{~nm}$, where no such absorption occurs. Qualitative plume absorbances captured in the camera plume images were converted to column amounts via a calibration procedure involving four quartz cells containing known $\mathrm{SO}_{2}$ columnamounts: $100,200,1000,2000$ ppm m; $\mathrm{SO}_{2}$ values within the plume were always within this range. The calibrations were performed at the time of measurement, by viewing clear sky adjacent to the plume, resulting in $R^{2}$ values $>0.99$ for the linear fitting. As the measurement conditions were favourable: e.g., the plume was transparent, the background sky was cloudless and the plume was $<4 \mathrm{~km}$ distant, additional DOAS based calibrations were not performed, as there is an excellent match between DOAS and cell based calibrations under such conditions (Lübcke etal., 2013). Under such circumstances we speculate that the measurement error was low, however, as radiative transfer has yet to become a routinely considered element of UV camera retrievals it is hard to provide an exact error budget in this case (e.g., Kern etal., 2009). For full details on all data capture, retrieval and calibration proceduresplease see Kantzas etal. (2010). All of these protocols were executedusing the Vulcamera code (Tamburello etal., 2011b).

The UV camera was located at the Pizzi Deneri observatory which provided a clear vantage point of the NEC plume, at a distance of $\approx 2 \mathrm{~km}$ (Fig. 1); the data were acquired between 08:45 and 09:45 GMT on the 12th of September 2012. Integrated column amount (ICA) values were determined by summing $\mathrm{SO}_{2}$ concentrations over the plume profile, perpendicular to its transport vector (Fig. 1). The emissionrates $\left(\mathrm{kg} \mathrm{s}^{-1}\right)$ were then found by multiplying ICAs by the plume transport speed, with the latter arising from cross-correlation analysis of the propagation of the plume across the field of view overa sequence of camera images (e.g. see McGonigle etal., 2005; WilliamsJones etal., 2006). The plume speed varied very little over the acquisition period ( $\approx 13.4 \mathrm{~m} \mathrm{~s}^{-1}$ throughout). The camera capture rate ranged between 0.5 and $1 \mathrm{~Hz}$ depending upon incident light levels, hence linear interpolation was applied, where necessary, to produce a uniform $1 \mathrm{~Hz}$ $\mathrm{SO}_{2}$ emission rates dataset.

The $\mathrm{CO}_{2} / \mathrm{SO}_{2}$ degassing ratios of the NEC were measured with a field portable Multi-GAS unit (Aiuppa etal., 2005; Shinohara, 2005) located at $\approx 100$ m downwind of the crater's vent, at a site chosen to avoid signal contamination from low-temperature fumarolic discharges (Shinohara etal., 2008). This unit extractively sampled the plume gases, providing $\mathrm{CO}_{2}$ and $\mathrm{SO}_{2}$ concentration readings at $\approx 0.5 \mathrm{~Hz}$ measurementfrequency. The $\mathrm{SO}_{2}$ concentrations were measured with an electrochemical sensor (City Technology, sensor type 3ST/F), of calibration range of 0-200 ppm, and the manufacturer quoted accuracy of $\pm 2 \%$, repeatability of $1 \%$ and a resolution of $0.5 \mathrm{ppm} \mathrm{v}$. The $\mathrm{CO}_{2}$ concentrations were measured with an infrared sensor (Edinburgh Instruments, Gascard II), of 0-3000 ppm v range, and with an accuracy of \pm $2 \%$ and a resolution of $0.8 \mathrm{ppm}$ v. Prior to the campaign, the Multi-GAS sensors were calibrated in the laboratory using standard gas cylinders of concentrations within the sensor ranges (e.g., 10 and $100 \mathrm{ppm} \mathrm{SO}_{2}$ and $3000 \mathrm{ppm} \mathrm{CO}_{2}$; all in nitrogen matrixes) and gas mixtures

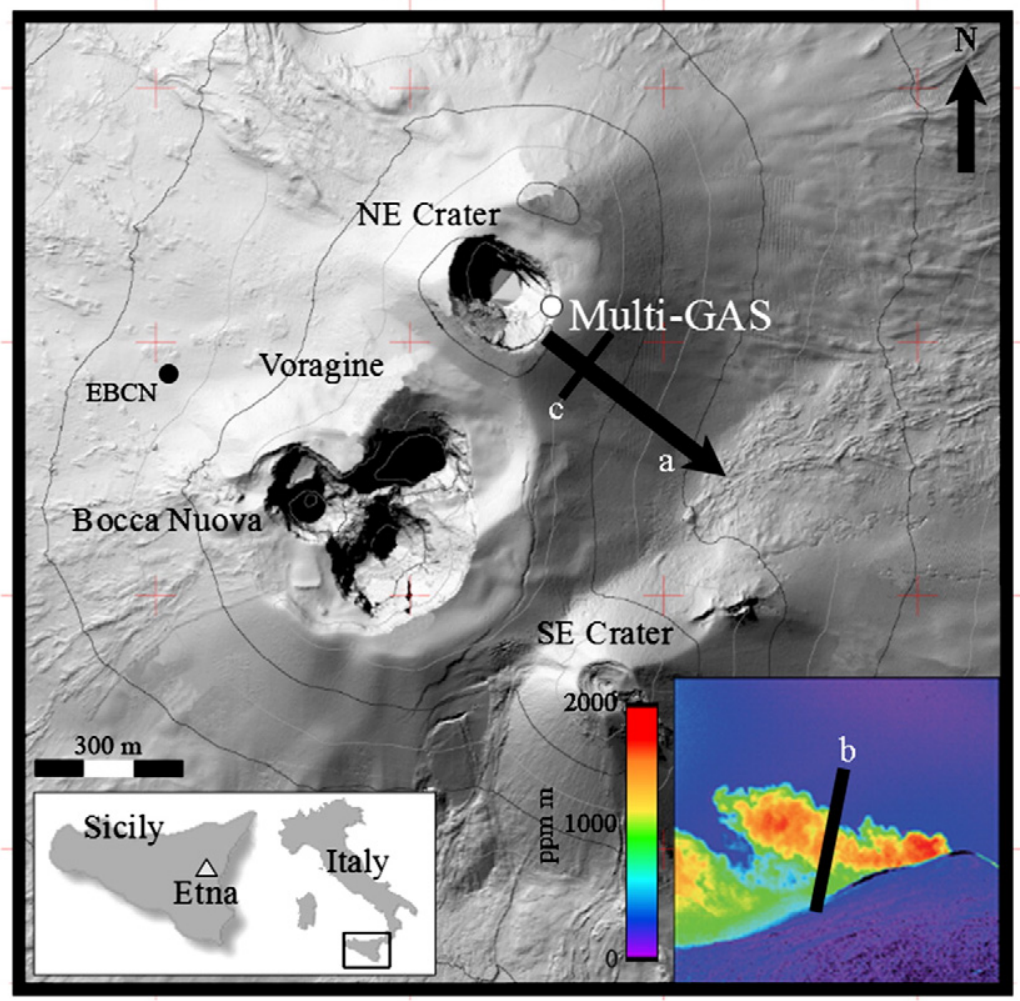

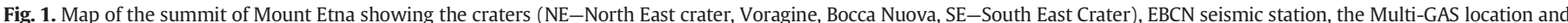

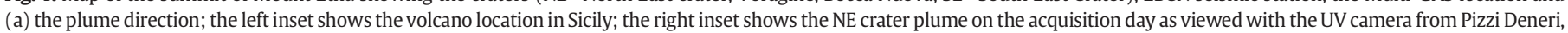

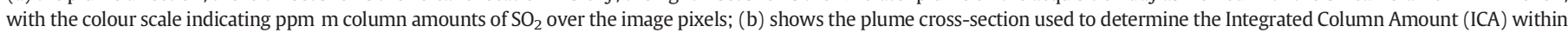
this inset; and (c), within the main image, the viewing vector corresponding to this profile with respect to the Multi-GAS location. 


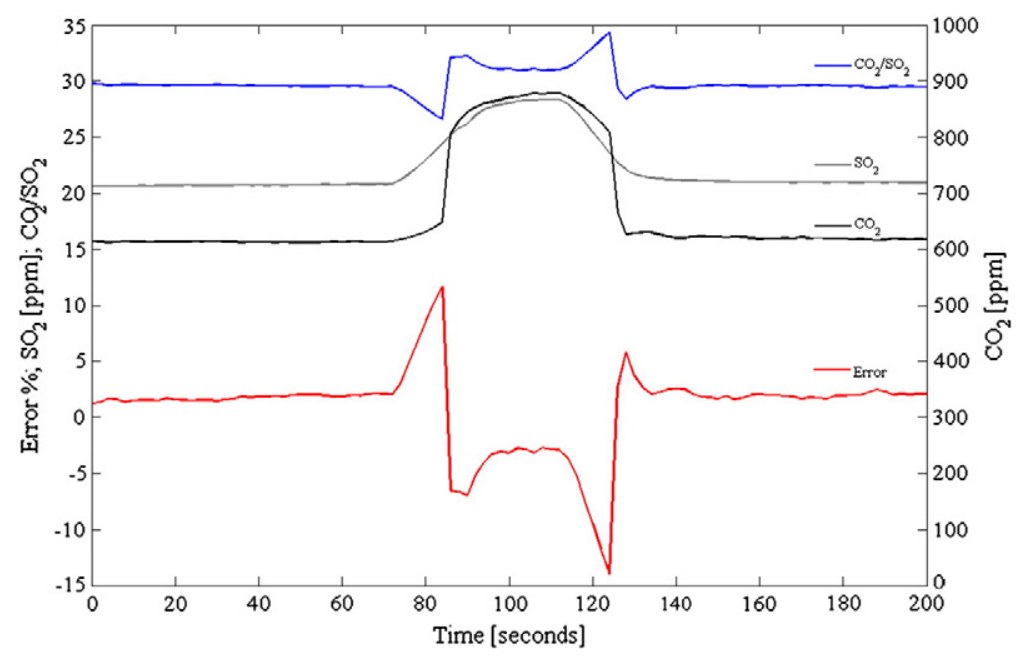

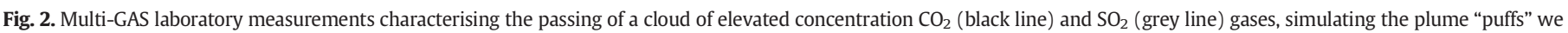

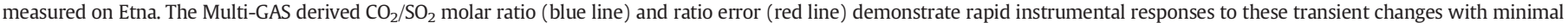
associated uncertainty ( $<15 \%)$.

correspondingapproximately to plume conditions (e.g., 10-30 ppm SO in air; e.g., with 380-900 ppm $\mathrm{CO}_{2}$ ). Pure nitrogen was used as zero reference in each case. These laboratory characterisations confirmed a typical measurement error in the $\mathrm{CO}_{2} / \mathrm{SO}_{2}$ ratios of $\leq 15 \%$.

An additional calibration test was performed to measure the response characteristics of the Multi-GAS sensors to rapid changes in gas fumigation, under the range of conditions we encountered during our field study. This was achieved by connecting three gas bottles of the following compositions: $79 \% \mathrm{~N}_{2}, 21 \% \mathrm{O}_{2}$ (e.g., the eluent); $79 \% \mathrm{~N}_{2}$, $21 \% \mathrm{O}_{2}, 3010 \mathrm{ppm} \mathrm{CO} ; 79 \% \mathrm{~N}_{2}, 21 \% \mathrm{O}_{2}, 100 \mathrm{ppm} \mathrm{SO}_{2}$, via regulators to the Multi-GAS inlet, to provide an overall flow rate of $1.21 \mathrm{~min}^{-1}$ into the instrument (e.g., as is typically the case for Multi-GAS field sampling). Firstly, the typical plume conditions were mimicked by setting the eluent flux to $0.721 \mathrm{~min}^{-1}$, and the $\mathrm{CO}_{2}$ and $\mathrm{SO}_{2}$ bottle fluxes to $0.241 \mathrm{~min}^{-1}$ each, which led to gas concentrations at the sensor of $615 \mathrm{ppm}$ and $20.4 \mathrm{ppm}$, respectively, for $\mathrm{CO}_{2}$ and $\mathrm{SO}_{2}$. The registered Multi-GAS ratios for such conditions are shown in Fig. 2 for $\mathrm{t}<70 \mathrm{~s}$ and $t>130 \mathrm{~s}$, leading to corresponding ratio errors of $<5 \%$. We also simulated rapid increases and decreases in gas concentration at the sensor ( $\mathrm{t} \approx 80 \mathrm{~s}, 125 \mathrm{~s} ;$ Fig. 2) to correspond to those we observed in the field, both in terms of timescale and magnitude, corresponding to the arrival and departure of more intense volcanogenic gas parcels. This was achieved by switching the eluent flux to/from $0.51 \mathrm{~min}^{-1}$ and the $\mathrm{CO}_{2}$ and $\mathrm{SO}_{2}$ fluxes concurrently to/from $0.35 \mathrm{l} \mathrm{min}^{-1}$, altering the concentrations to/from $29 \mathrm{ppm}$ and $878 \mathrm{ppm}$, respectively for $\mathrm{SO}_{2}$ and $\mathrm{CO}_{2}$. As shown in Fig. 2, the ratio in error remained within $\pm 15 \%$ during these transitions, confirming the ability of the Multi-GAS to respond rapidly to these changes in plume fumigation, given typical $t_{90 \%}$ values of $\approx 10$ s for both the Multi-GAS SO 2 and $\mathrm{CO}_{2}$ sensors ( $t_{90 \%}$ corresponds to the time between standard gas injection and the instrumental signal reaching $90 \%$ of the plateau value). Hence, this provides confidence that any field observed changes in gas ratios could not be artefacts of differing instrumental response times. Indeed, Fig. 3b shows a zoomed sectionof the acquired Multi-GAS time-series showing the similar response characteristics of the two sensors to volcanogenic changes in the concentrations of both species. Atmospheric background $\mathrm{CO}_{2}$ values were determined by plotting raw $\mathrm{CO}_{2}$ values with $\mathrm{SO}_{2}$ on a scatter plot. The intercept of the regression line with the axis is taken as the background level, in this case a value of $\approx 200 \mathrm{ppm}$. Temporal synchronicity with the UV camera $\mathrm{SO}_{2}$ emission rate data series, throughout the one hour observation period, was ensured by time referencing both instruments' data series with GPS receiver outputs. Linear interpolation was applied to the Multi-GAS ratio data to temporally match these data to the $1 \mathrm{~Hz}$ UV camera $\mathrm{SO}_{2}$ emission rates.
The ICA determination for the $\mathrm{NEC} \mathrm{SO}_{2}$ emission rate calculation was made at $\approx 180$ m downwind of the GPS receiver geo-referenced MultiGAS measurement location. The UV camera derived plume speeds were then used to derive temporal lags between the gas emission rate and gas ratio time series ( $\approx 13 \mathrm{~s}$ throughout the acquisition), enabling shifting of the series relative to one another by this lag value to account for the slight offset between the plume locations viewed/sampled by the two techniques. This procedure provided excellent overlap between peaks and troughs in the gas concentration and emission rate series as the volcanogenic source signal fluctuated (Fig. $3 \mathrm{~b}$ ) and also serves to offset the small Multi-GAS sensor lag. A lag of $\approx 13 \mathrm{~s}$ is also achieved when cross-correlating the UV camera $\mathrm{SO}_{2}$ emission rate with Multi-GAS $\mathrm{SO}_{2}$ readings, further corroborating our procedure.

\section{Results and discussion}

The acquired NEC Multi-GAS $\mathrm{CO}_{2}$ vs. $\mathrm{SO}_{2}$ concentrations are plotted in Fig. 3a, demonstrating a general trend (with a mean molar ratio of $0.5 \pm 0.07$, based on the largest, e.g., $\pm 15 \%$, uncertainty encountered during our laboratory sensor characterisations) between emissions of the two species, with the exception of large spikes in $\mathrm{CO}_{2}$ emissions within the shaded grey oval. Since the Multi-GAS measurement location was chosen with great care to completely avoid fumarolic discharges, we exclude the possibility that this feature could arise from contamination by these sources. Given that these spikes were also closely temporally aligned to peaks in seismicity, the source of which was located under the NEC at the time of measurements, as discussed further below, this is also suggestive that these trends were indeed related to activity at the NEC.

Each molar $\mathrm{CO}_{2} / \mathrm{SO}_{2}$ gas ratio datum (Fig. 3d), was converted to a mass ratio on the basis of the species' relative molecular weights and then multiplied by the temporally coincident $\mathrm{SO}_{2}$ emission rate (Fig. 3f) to deliver the $\mathrm{CO}_{2}$ emission rate time series shown in Fig. 3e, demonstrating significant variability in emissions, spanning two orders of magnitude (from $\approx 0.1$ to $12 \mathrm{~kg} \mathrm{~s}^{-1}$ ), over timescales of tens to hundreds of seconds. These fluxes are subject to errors of $\pm 15 \%$ arising from the gas ratios, on the basis of our aforementioned experimental characterisations, however errors arising from the $\mathrm{SO}_{2}$ fluxes are not considered here for the reasons detailed above. This observation of fluctuation in $\mathrm{CO}_{2}$ degassing, in tandem with our reported methodology, has the potential to add to our understanding of $\mathrm{CO}_{2}$ degassing trends and of their importance in volcanic loading of the atmosphere.

The acquisition averaged $\mathrm{NEC} \mathrm{CO} / \mathrm{SO}_{2}$ molar ratio of $0.5 \pm 0.07$ was low although not unusual for this crater, where the degassing activity is 

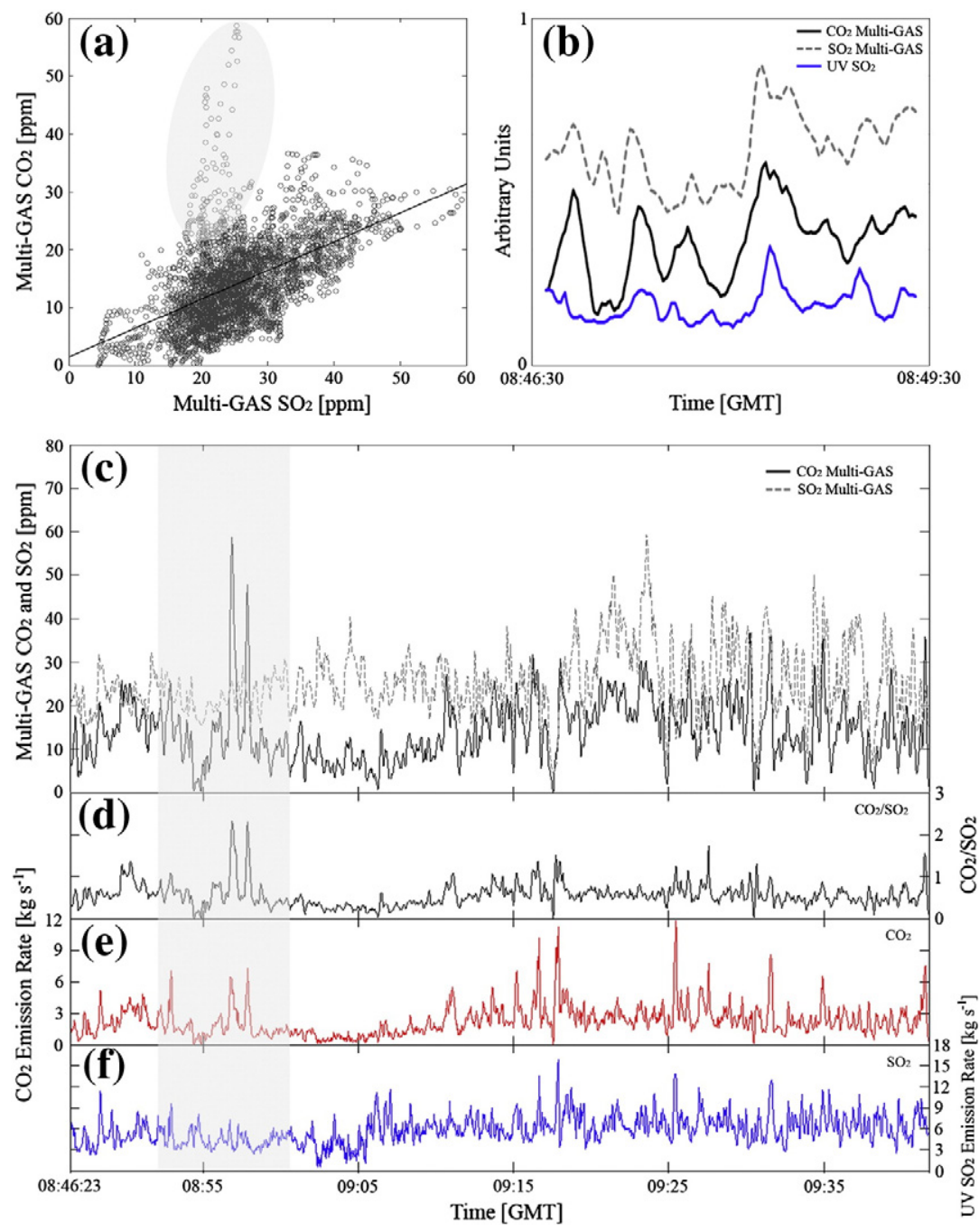

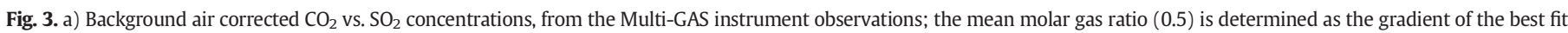

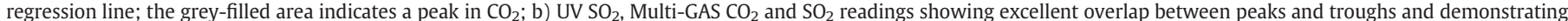

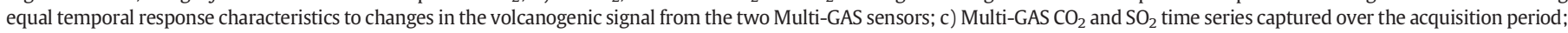
d) the molar ratio of $\mathrm{CO}_{2} / \mathrm{SO}_{2}$; e) the $\mathrm{CO}_{2}$ emission rate and f) $\mathrm{SO}_{2}$ emission rate across the acquisition period.

often sourced by more evolved (e.g., more volatile-depleted) magmas than those supplying the central craters' (CCs) plumes (Aiuppa etal., 2006, 2008). Likewise, the mean $\mathrm{NEC} \mathrm{CO}_{2}$ emission rate and $\mathrm{SO}_{2}$ emission rates captured in our dataset were also rather low, although not unprecedentedly so: at $2 \mathrm{~kg} \mathrm{~s}^{-1}$ and $6 \mathrm{~kg} \mathrm{~s}^{-1}$, respectively. On the day of the measurements the majority of Etna's degassing arose from the CCs, with combined Voragine and Bocca Nuova $\mathrm{CO}_{2}$ and $\mathrm{SO}_{2}$ emission rates of $86 \mathrm{~kg} \mathrm{~s}^{-1}$ and $14 \mathrm{~kg} \mathrm{~s}^{-1}$, respectively; these data were acquired by us with our Multi-GAS and UV camera unit and are consistent with previous evaluations (e.g., Aiuppa etal., 2008). Whilst this NEC contribution was only a fraction of Etna's gas budget, these observations do provide the opportunity, for the first time, to characterise the short term $\mathrm{CO}_{2}$ degassing behaviour of an active volcano, and any periodicities observed therein. Studying this behaviour for the other craters will be a key target of future work.

Periodicity in $\mathrm{SO}_{2}$ release, on short timescales, has been reported from a few volcanoes worldwide (e.g., Boichu et al., 2010; Nadeau et al., 2011; Tamburello et al., 2012, 2013). Periodicity was investigated in our $\mathrm{CO}_{2}, \mathrm{SO}_{2}$ and contemporaneous geophysical data using a continuous Morlet wavelet transform technique (see Fig. 4). This approach involves scaling a defined oscillation (a Morlet wavelet), and mathematically assessing similarities between the acquired data and the scaled wavelet. This signal processing technique is often used in the analysis of environmental processes due to its effectiveness in detecting natural oscillations (Morlet etal., 1982), such as climatic variability (Jevrejeva et al., 2003). This technique is preferred to other time series analysis as information is gleaned on the stability of periodicities present at a given time. Given the duration of our acquisition, the longest resolvable oscillation period via this analysis was $512 \mathrm{~s}$ according to the Nyquist theorem (Nyquist, 2002), hence the plots in Fig. 4 are cropped accordingly.

Fig. 4 shows non-stationary degassing behaviour in the $\mathrm{NEC} \mathrm{CO}_{2}$ and $\mathrm{SO}_{2}$ Morlets with characteristic periodicities between $\approx 40$ and $500 \mathrm{~s}$. Oscillations in this period range are also apparent in Morlet analysisof contemporaneously acquired seismic data (Fig. 4d). Thedominant modulation frequencies in the degassing data were assessed withpower spectral densities (PSDs) using Welch's method (Welch, 1967), applied after normalization of the data. The resultant periodograms show the power of manifest oscillations across this period range (see Fig. 4), revealing the dominant peak for $\mathrm{CO}_{2}$ emission rates at $\approx 89 \mathrm{~s}$; a peak matching this period is also evident in the $\mathrm{SO}_{2}$ data, and the dominant peak in $\mathrm{CO}_{2} / \mathrm{SO}_{2}$ ratios also falls here $(\approx 85 \mathrm{~s})$. The latter result strongly implies that the observed non-stationary degassing signals are indeed volcanogenic in origin and not an artefact of atmospheric transport processes which would not generate any modulation in sampled gas ratios. Furthermore, the presence of the $\approx 89 \mathrm{~s}$ signal in both $\mathrm{CO}_{2}$ and $\mathrm{SO}_{2}$ emission rate PSDs suggests that a common source process is generating the periodicity in both cases. 


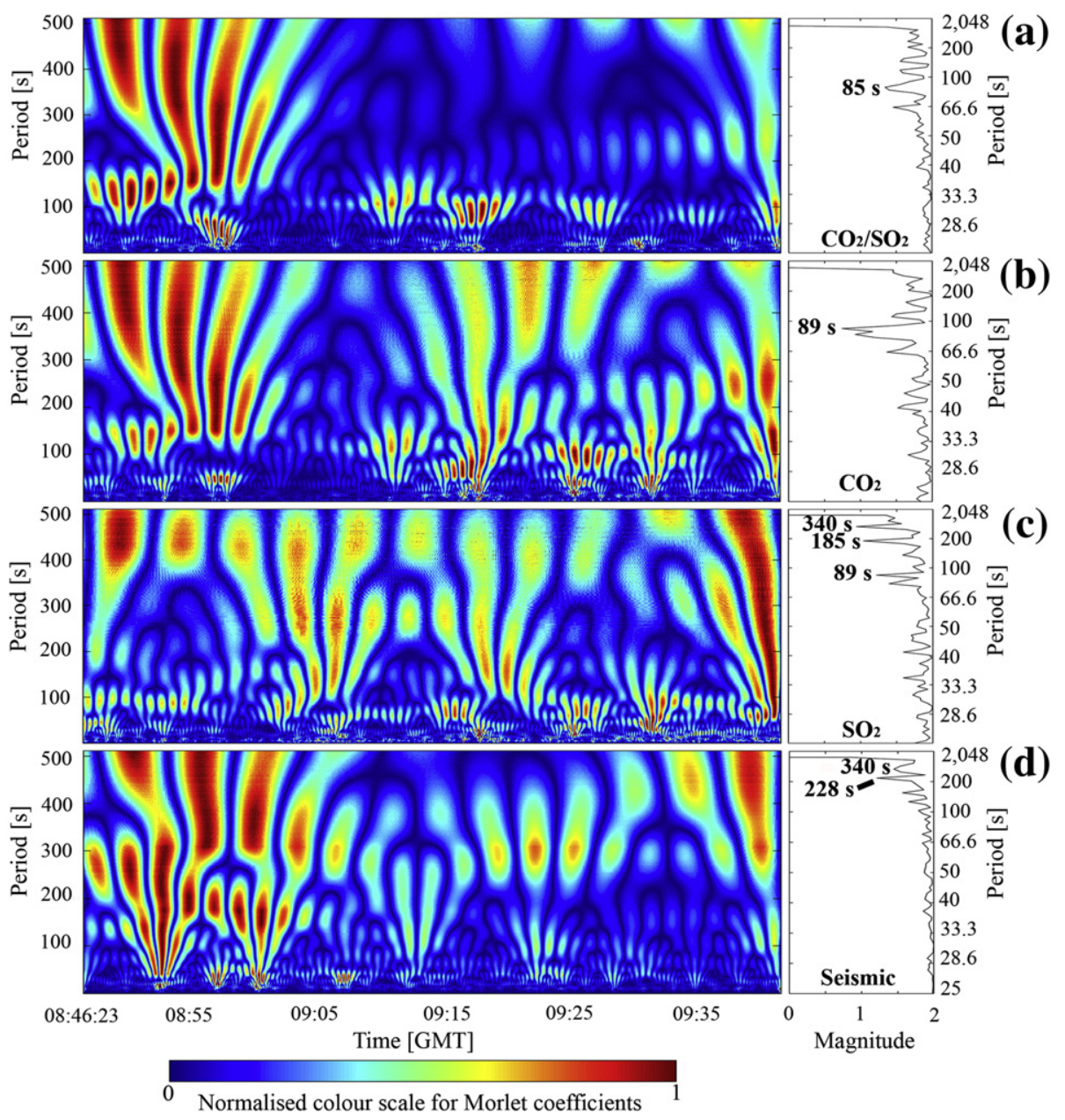

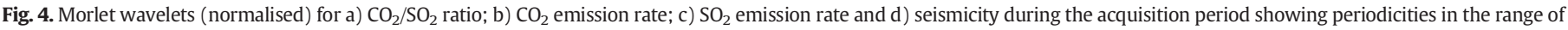
40-500 s; Welch power spectral density plots are also shown, indicating the dominant frequencies in each case.

There are many physical processes which could potentially drive the observed modulations in gas emission rates and ratios. These include: (1) convection of magma in the conduit and/or the shallow to deep plumbing system (Kazahaya etal., 1994; Boichu etal., 2010); as convectionis likely a non-stationary process, this could involve varying overturnrate, leading to modulation in gas release; (2) pulsatory supply of volatile rich magmas into the conduit; on Mt. Erebus, this has been proposed to introduce a consequent periodicity in emissions at the magma surface (Oppenheimer etal., 2009); (3) changes in the volatile content of the magma or supply of volatiles from depth (Kazahaya etal., 2002), in which depressurisation based exsolution of gases from the melt could, itself, lead to a periodicity in gas sourcing; (4) short to long term changes in rheology of the magma (Koyaguchi etal., 1993); such trends in magma viscosity would act to vary gas transit speed throughout the plumbing system; and (5) interaction of magma and entrained volatiles with geometric discontinuities in the conduit or shallow storage zones (James etal., 2006; Palma etal., 2011); such features could cause periodic collection and release of bubbles, by analogy with the collapsing foam model for strombolian activity (Jaupart and Vergniolle, 1988; Vergniolle and Brandeis, 1994). Further work based on an expanded dataset is now required to investigate, in more detail, the relevance of each of these models in this volcanic context, by assessing the variation and stability of emission rate periodicities in time and their links to geophysical signals.

In the context of this study we investigated the relationship between periodicities manifested in the various captured datasets. This was achieved by correlating the coefficients produced by the Morlet wavelet analysis for the $\mathrm{CO}_{2}$ and $\mathrm{SO}_{2}$ emission rate and seismic data (Fig. 5), in order to establish the degree to which oscillations at a particular period demonstrated common strength and phase between the series. This is preferable to correlating the raw signals as it eliminates rapid variability, hence more clearly resolves where dominant fluctuations are shared across the data streams. There is a clear link between the periodicities present in $\mathrm{CO}_{2}$ and $\mathrm{SO}_{2}$ emissions up to $\approx 250 \mathrm{~s}$ where the link breaks down for around $50 \mathrm{~s}$, before resuming, then peaking at $\approx 500 \mathrm{~s}$ (Fig. 5a). Note that discussion of a possible gas-infrasonic relationship is not included here as any link, if present, was obscured by high wind pollution in the acoustic dataset. The seismic vs. $\mathrm{CO}_{2}$ emission rate analysis reveals an intriguing negative correlation $(<-0.5$; Fig. $5 \mathrm{~b})$ for periods between 300 and $400 \mathrm{~s}$, which corresponds to the period range where the relationship between $\mathrm{CO}_{2}$ and $\mathrm{SO}_{2}$ emissions breaks down (Fig. 5a).

This anti-correlation is suggestive of a possible temporal lag between oscillations at these frequencies in the seismic and $\mathrm{CO}_{2}$ emission rate series, which we investigated further by performing, each second, a mathematical integration of the Morlet coefficients, between 300 and $400 \mathrm{~s}$ for the seismic, $\mathrm{CO}_{2} / \mathrm{SO}_{2}$ and $\mathrm{CO}_{2}$ emission rate series, to generate the output shown in Fig. $6 \mathrm{~b}$. These three traces all show distinctive peaks between $\approx 08: 50$ and $\approx 09: 00$ GMT, e.g., the time intervals shaded grey in Figs. 3 and 6, where elevated wavelet coefficients in this period range (Fig. 4a, b and d) demonstrated strong oscillations therein, and the $\mathrm{CO}_{2} / \mathrm{SO}_{2}$ ratios spike to high values (Fig. 3a). The two gas peaks in the shaded area of Fig. $6 \mathrm{~b}$ preceded those in the seismic record by $100-150 \mathrm{~s}$, and indeed, moving forward the seismic record in time by $125 \mathrm{~s}$ and correlating led to a correlation coefficient of $\approx 0.9$ in this time window. Therefore, given the absence of any seismic events prior to these gas spikes, this could well imply the existence of a process 


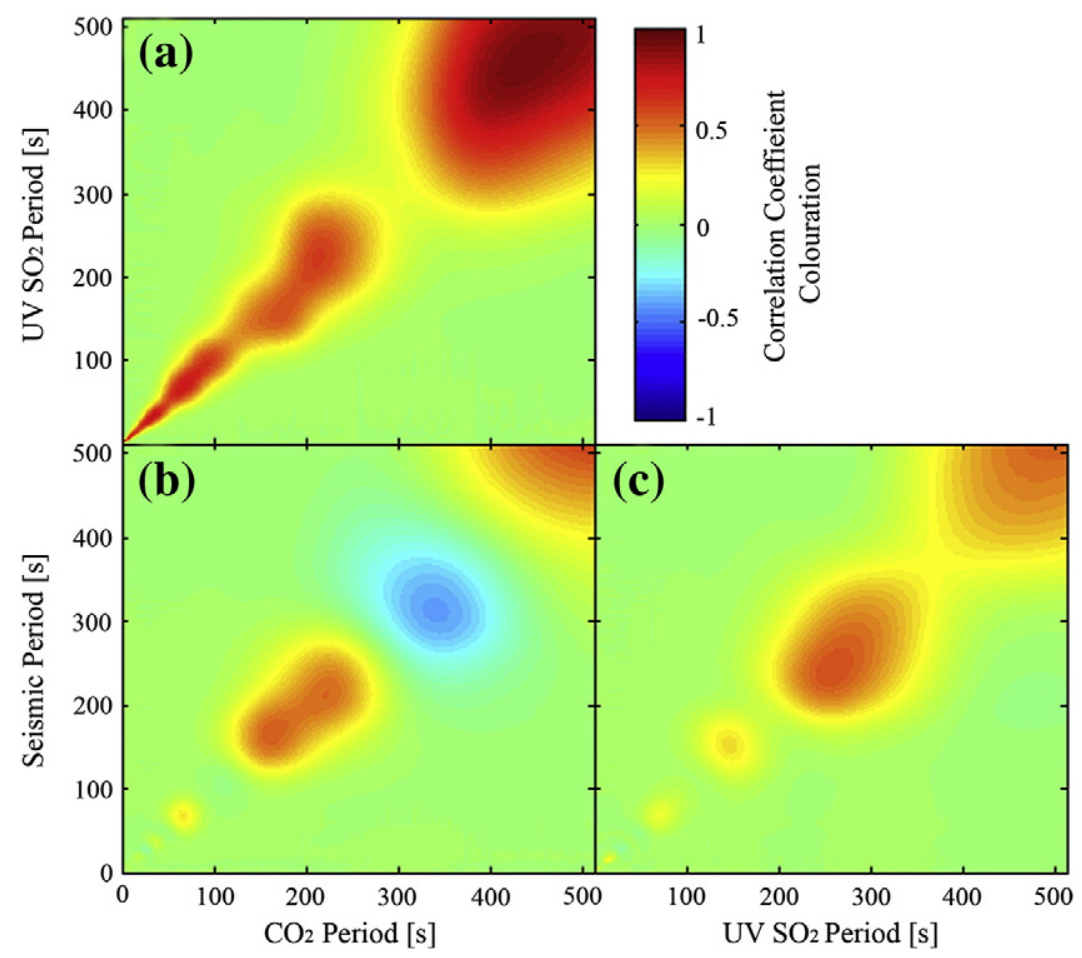

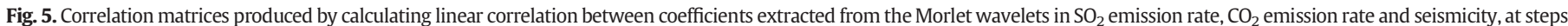

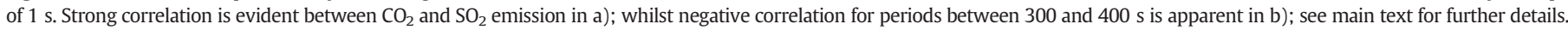

causing elevated $\mathrm{CO}_{2}$ emissions to be released from the vent some $150 \mathrm{~s}$ prior to peaks in seismicity. Transit time of gas from the source to measurement location is $<30 \mathrm{~s}$. Our observations might also be indicative of a model of quite the opposite nature, in that a small NW displacement in tremor location occurred at a depth of $\approx 500-1000$ m between $\approx 09: 10$ and 09:15 (Personal Communication, Giuseppe Di Grazia, INGV), is followed by several large peaks in gas emissions, $\approx 500-900$ s later, which corresponds to realistic travel times for gas rise from such depths (Manga, 1996).

Regardless of the possible lag direction, a mechanism involving themovement of magma and/or entrained volatiles, induced by changesin pressure or temperature, could be invoked. Peaks in the gases' $\mathrm{CO}_{2} / \mathrm{SO}_{2}$ ratios could be caused by a deeper than average pressure base i.e. a greater source depth. A system-wide increase in temperature could also drive a long-term increase in ratios by facilitating the transport of volatiles from depth; a localised temperature increase, through injection of fresh magma, might also therefore, in theory, temporarily reproduce the same effect. Each of these processes could generate seismicity, due to migration of magmas and/or volatiles, followed by elevated gas emissions. An opposite hypothesis could involve a model based on readjustment of the magma level, with corresponding seismic energy generation,following release of gases at the surface. These tentative hypotheses,based on our initial observations, are presented as avenuesfor future work, in which longer datasets are required to furtherinvestigate the direction of any manifest lag between seismic and degassing data, with a view to better characterising the associated underground magmatic processes.

\section{Concluding remarks}

Here we report for the first time the combined use of a field portable Multi-GAS sensor and UV camera imaging to produce a high time resolution $(\approx 1 \mathrm{~Hz})$ volcanic $\mathrm{CO}_{2}$ emission rate dataset, in this case from Mt. Etna's North East crater. The development of such a methodology has significant implications for the study of short and long term degassing trends and improved integration between degassing and geophysical

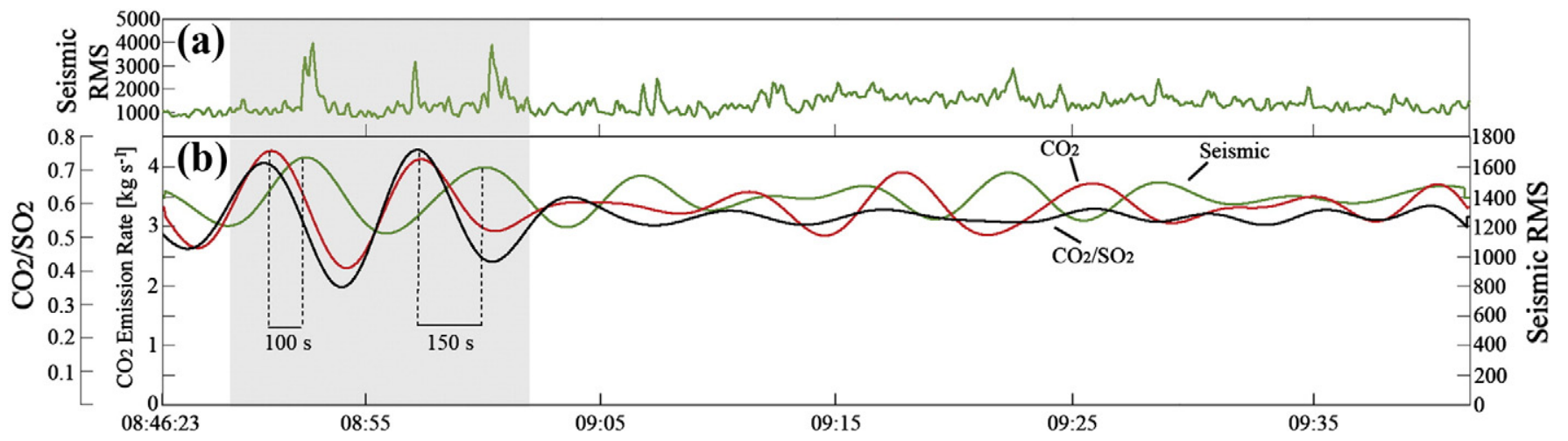

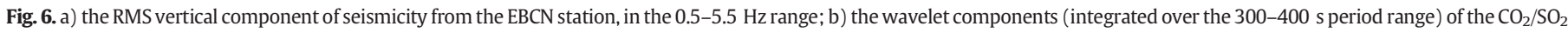

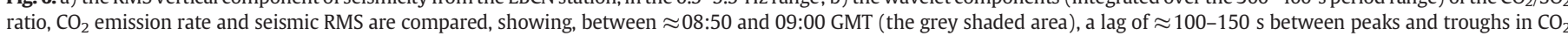
emissions and seismicity. 
datasets. We demonstrate that $\mathrm{CO}_{2}$ emissions are highly variable, spanning two orders of magnitude, on timescales of tens to hundreds of seconds.This technique is therefore significant in respect of attempts to assess global volcanogenic $\mathrm{CO}_{2}$ emission rates. We furthermore establishthat both the $\mathrm{CO}_{2}$ emission rates and $\mathrm{SO}_{2}$ emission rates, in additionto the $\mathrm{CO}_{2} / \mathrm{SO}_{2}$ ratios, exhibit prominent common periodicities at $\approx 89 \mathrm{~s}$ and that our results are suggestive of an intriguing lag between $\mathrm{CO}_{2}$ and seismic oscillations, with periods of around 300 $400 \mathrm{~s}$, possibly indicative of a process involving the movement of magma in the conduit. This work paves the way for further high time resolution investigations into degassing of $\mathrm{CO}_{2}$ at Mount Etna and other basaltic volcanoes worldwide to expand our understanding of degassing dynamics and links to manifest geophysical signals.

\section{Acknowledgements}

TDP and AMcG acknowledge the support of a NERC studentship, the University of Sheffield and a Google Faculty Research award. AA acknowledgessupport from the European Research Council Starting IndependentResearch Grant (agreement number 1305377). Data presentedin this paper were obtained during the "Etna-Pizzi Deneri field trip" organized and supported by the Università degli Studi di Palermoand INGV sezione di Catania and Palermo. We thank Giuseppe Di Grazia (INGV sezione di Catania) for seismic tremor locations. We are finally grateful to Cynthia Werner and Toshiya Mori for their reviews which have greatly improved the quality of this paper.

\section{References}

Aiuppa, A., Federico, C., Paonita, A., Giudice, G., Valenza, M., 2005. Chemical mapping of a fumarolic field: La Fossa Crater, Vulcano Island (Aeolian Islands, Italy). Geophys. Res. Lett. 13, L13309. http://dx.doi.org/10.1029/2005GL023207.

Aiuppa, A., Federico, C., Giudice, G., Gurrieri, S., Liuzzo, M., Shinohara, H., Favara, R. Valenza, M., 2006. Rates of carbon dioxide plume degassing from Mount Etna volcano. J. Geophys. Res. 111 (B09207). http://dx.doi.org/10.1029/2006JB004307.

Aiuppa, A., Moretti, R., Federico, C., Giudice, G., Gurrieri, S., Liuzzo, M., Papale, P. Shinohara, H., Valenza, M., 2007. Forecasting Etna eruption by real time evaluation of volcanic gas composition. Geology 35 (12), 1115-1118.

Aiuppa, A., Giudice, G., Gurrieri, S., Liuzzo, M., Burton, M., Caltabiano, T., McGonigle, A.J.S., Salerno, G., Shinohara, H., Valenza, M., 2008. Total volatile flux from Mount Etna. Geophys. Res. Lett. 35, L24302. http://dx.doi.org/10.1029/2008GL035871.

Aiuppa, A., Burton, M., Caltabiano, T., Giudice, G., Guerrieri, S., Liuzzo, M., Mure, F., Salerno, G., 2010. Unusually large magmatic $\mathrm{CO}_{2}$ gas emissions prior to a basaltic paroxysm. Geophys. Res. Lett. 37, L17303. http://dx.doi.org/10.1029/2010GL043837.

Aiuppa, A., Burton, M., Allard, P., Caltabiano, T., Giudice, G., Gurrieri, S., Liuzzo, M., Salerno, G., 2011. First observational evidence for the CO2-driven origin of Stromboli's majorexplosions. J. Geophys. Res. Solid Earth 2 (2), 135-142. http://dx.doi.org/ $10.5194 / \mathrm{se}-2-135-2011$.

Allard, P., Carbonnelle, J., Dajlevic, D., Le Bronec, J., Morel, P., Robe, M.C., Maurenas, J.M., Faivre-Pierret, R., Martin, D., Sabroux, J.C., Zettwoog, P., 1991. Eruptive and diffuse emissions of $\mathrm{CO}_{2}$ from Mount Etna. Nature 351, 387-391.

Allard, P., Behncke, B., D'Amico, S., Neri, M., Gambino, S., 2006. Mount Etna 1993-2005: anatomy of an evolving eruptive cycle. Earth-Sci. Rev. 78, 85-114.

Boichu, M., Oppenheimer, C., Tsanev, V., Kyle, P., 2010. High temporal resolution $\mathrm{SO}_{2}$ flux measurements at Erebus volcano, Antarctica. J. Volcanol. Geotherm. Res. 190, 325-336.

Carroll, M.R., Holloway, J.R. (Eds.), 1994. Volatiles in Magmas. Mineralogical Society of America Reviews in Mineralogy, 30 (Washington, D. C.).

Gerlach, T.M., 1991. Present-day $\mathrm{CO}_{2}$ emissions from volcanoes. EOS Trans. AGU 72 (249), 254-255.

Gerlach, T.M., McGee, K.A., Elias, T., Sutton, A.J., Doukas, P., 2002. Carbon dioxide emission rate of Kilauea Volcano: implications for primary magma and the summit reservoir. J. Geophys. Res. 107 (B9), 2189. http://dx.doi.org/10.1029/2001JB000407.

Giggenbach, W.F., 1996. Chemical Composition of Volcanic Gases. In: Scarpa, R., Tilling, R.I. (Eds.), Monitoring and Mitigation of Volcanic Hazards. Springer, New York, pp. 221-256.

James, M.R., Lane, S.J., Chouet, B.A., 2006. Gas slug ascent through changes in conduit diameter: laboratory insights into a volcano-seismic source process in low-viscosity magmas. J. Geophys. Res. 111 (B05201). http://dx.doi.org/10.1029/2005JB003718.

Jaupart, C., Vergniolle, S., 1988. Laboratory models of Hawaiian and Strombolian eruptions. Nature 331, 58-60.

Jevrejeva, S., Moore, J.C., Grinsted, A., 2003. Influence of the Arctic Oscillation and El NiñoSouthern Oscillation (ENSO) on ice conditions in the Baltic Sea: the wavelet approach. J. Geophys. Res. Atm. 108 (D21). http://dx.doi.org/10.1029/2003JD003417.

Kantzas, E.P., McGonigle, A.J.S., Tamburello, G., Aiuppa, A., Bryant, R.G., 2010. Protocols for UV camera volcanic $\mathrm{SO}_{2}$ measurements. J. Volcanol. Geoth. Res. 194, 55-60.

Kazahaya, K., Shinohara, H., Saito, G., 1994. Excessive degassing of Izu-Oshima volcano: magma convection in a conduit. B. Volcanol. 56, 207-216.
Kazahaya, K., Shinohara, H., Saito, G., 2002. Degassing process of Satsuma-Iwojima volcano, Japan: supply of volatile components from a deep magma chamber. Earth Planets Space 54, 327-335

Kern, C., Deutschmann, T., Vogel, L., Wöhrbach, M., Wagner, T., Platt, U., 2009. Radiative transfer corrections for accurate spectroscopic measurements of volcanic gas emissions. Bull. Volcanol. 72, 233-247. http://dx.doi.org/10.1007/s00445-009-0313-7.

Koepenick, K., Brantley, S., Thompson, J., Rowe, G., Nyblade, A., Moshy, C., 1996. Volatile emissions from the crater and flank of Oldoinyo Lengai volcano, Tanzania. J. Geophys. Res. 10, 13,819-13,830.

Koyaguchi, T., Hallworth, M.A., Huppert, H.E., 1993. An experimental study on the effects of phenocrysts on convection in magmas. J. Volcanol. Geoth. Res. 55, 15-32.

Lübcke, P., Bobrowski, N., Illing, S., Kern, C., Alvarez Nievez, J.M., Vogel, L., Zielcke, J., Delgado, Granados H., Platt, U., 2013. On the absolute calibration of $\mathrm{SO}_{2}$ cameras. Atmos. Meas. Tech. 6, 677-696. http://dx.doi.org/10.5194/amt-6-677-2013.

Manga, M., 1996. Waves of bubbles in basaltic magmas and lavas. J. Geophys. Res. 101 (B8), 17,457-17,465.

McGonigle, A.J.S., Hilton, D.R., Fischer, T.P., Oppenheimer, C., 2005. Plume velocity determination for volcanic SO2 flux measurements. Geophys. Res. Lett. 32, L11302. http://dx.doi.org/10.1029/2005GL022470.

Mori, T., Burton, M., 2006. The SO2 camera: a simple, fast and cheap method for groundbased imaging of SO2 in volcanic plumes. Geophys. Res. Lett. 33, L24804. http:// dx.doi.org/10.1209/2006GL027916.

Morlet, J., Arens, G., Fougeau, E., Giard, D., 1982. Wave propagation and sampling theory; Part I, complex signal and scattering in multilayered media. Geophysics 47 (2), 203-221.

Nadeau, P.A., Palma, J.L., Waite, G.P., 2011. Linking volcanic tremor, degassing, and eruption dynamics via SO2 imaging. Geophys. Res. Lett. 38, L01304. http://dx.doi.org/ 10.1029/2010GL045820.

Nyquist, H., 2002. Certain topics in telegraph transmission theory (Reprinted from Transactions of the A. I. E. E., February, pg 617-644, 1928). Proc. IEEE 90 (2), 280-305. http://dx.doi.org/10.1109/5.989875.

Oppenheimer, C., Lomakina, A.S., Kyle, P.R., Kingsbury, N.G., Boichu, M., 2009. Pulsatory magma supply to a phonolite lava lake. Earth Planet. Sci. Lett. 284, 392-398.

Palma, J.L., Blake, S., Calder, E.S., 2011. Constraints on the rates of degassing and convection in basaltic open-vent volcanoes. Geochem. Geophys. Geosyst. 12 (11). http:// dx.doi.org/10.1029/2011GC003715.

Poland, M.P., Miklius, A., Sutton, A.J., Thornber, C.R., 2012. A mantle-driven surge in magma supply to Kilauea Volcano during 2003-2007. Nat. Geosci. 5 (4), 295-297. http://dx.doi.org/10.1038/NGEO1426.

Shinohara, H., 2005. A new technique to estimate volcanic gas composition: plume measurements with a portable multi-sensor system. J. Volcanol. Geotherm. Res. 143, 319-333.

Shinohara, H., Aiuppa, A., Giudice, G., Gurrieri, S., Liuzzo, M., 2008. Variation of $\mathrm{H}_{2} \mathrm{O} / \mathrm{CO}_{2}$ and $\mathrm{CO}_{2} / \mathrm{SO}_{2}$ ratios of volcanic gases discharged by continuous degassing of Mount Etna volcano, Italy. J. Geophys. Res. 113 (B09203). http://dx.doi.org/10.1029/ 2007JB005185

Spilliaert, N., Allard, P., Métrich, N., Sobolev, A.V., 2006. Melt inclusion record of the conditions of ascent, degassing, and extrusion of volatile-rich alkali basalt during the powerful 2002 flank eruption of Mount Etna (Italy). J. Geophys. Res. 111 (B04203). http://dx.doi.org/10.1029/2005JB003934.

Tamburello, G., Kantzas, E.P., McGonigle, A.J.S., Aiuppa, A., 2011a. Recent advances in ground-based ultraviolet remote sensing of volcanic $\mathrm{SO}_{2}$ fluxes. Ann. Geophys. 54 (2), 199-208.

Tamburello, G., Kantzas, E.P., McGonigle, A.J.S., Aiuppa, A., 2011b. Vulcamera: a program for measuring volcanic $\mathrm{SO}_{2}$ using UV cameras. Ann. Geophys. 54 (2), 219-221.

Tamburello, G., Aiuppa, A., Kantzas, E.P., McGonigle, A.J.S., Ripepe, M., 2012. Passive vs. active degassing modes at an open-vent volcano (Stromboli, Italy). Earth Planet. Sci. Lett. 359-360, 106-116.

Tamburello, G., Aiuppa, A., McGonigle, A.J.S., Allard, P., Cannata, A., Giudice, G., Kantzas, E.P., Pering, T.D., 2013. Periodic volcanic degassing behaviour: the Mount Etna example. Geophys. Res. Lett. 40, 1-5. http://dx.doi.org/10.1002/grl.50924.

Vergniolle, S., Brandeis, G., 1994. Origin of the sound generated by Strombolian explosions. J. Geophys. Res. 21, 1959-1962.

Wardell, L.J., Kyle, P.R., Chaffin, C., 2004. Carbon dioxide and carbon monoxide emission rates from an alkaline intra-plate volcano: Mt. Erebus, Antarctica. J. Volcanol. Geoth. Res. 131 (1-2), 109-121.

Welch, P.D., 1967. The use of fast Fourier transform for the estimation of power spectra: a method based on time averaging over short, modified periodograms. IEEE Trans. Audio Electroacoustics AU-15 (2), 70-73.

Werner, C., Christenson, B.W., Hagerty, M., Britten, K., 2006. Variability of volcanic gas emissions during a crater lake heating cycle at Ruapehu Volcano, New Zealand. J. Volcanol. Geoth. Res. 154 (3-4), 291-302.

Werner, C., Hurst, T., Scott, B., Sherburn, S., Christenson, B.W., Britten, K., Cole-Baker, J., Mullan, B., 2008. Variability of passive gas emissions, seismicity, and deformation during crater lake growth at White Island Volcano, New Zealand, 2002-2006. J. Geophys. Res. Solid Earth 113 (B1). http://dx.doi.org/10.1029/2007JB005094.

Werner, C., Kelly, P.J., Doukas, M., Lopez, T., Pfeffer, M., McGimsey, R., Neal, C., 2012a. Degassing of $\mathrm{CO}_{2}, \mathrm{SO}_{2}$, and $\mathrm{H}_{2} \mathrm{~S}$ associated with the 2009 eruption of Redoubt Volcano, Alaska. J. Volcanol. Geotherm. Res. http://dx.doi.org/10.1016/j.volgeores.2012.04.012.

Werner, C. Evans, W.C. Kelly, P.J., McGimsey, R, Pfeffer, M. Doukas, M., Neal, C., 2012b. Deep magmatic degassing versus scrubbing: Elevated $\mathrm{CO}_{2}$ emissions and $\mathrm{C} / \mathrm{S}$ in the lead-up to the 2009 eruption of Redoubt Volcano, Alaska. Geochem. Geophys. Geosyst. 13 (3). http://dx.doi.org/10.1029/2011GC003794.

Williams-Jones, G., Horton, K.A., Elias, T., Garbeil, H., Mouginis-Mark, P.J., Sutton, A.J., Harris, A.J.L., 2006. Accurately measuring volcanic plume velocity with multiple UVspectrometers. B. Volcanol. 68, 328-332. http://dx.doi.org/10.1007/s00445-0050013-x. 